\title{
اقتصاديات الصالح العام
}

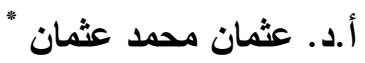

\section{مقدمة:}

كتبت فى عدد ديسمبر Y V P من هذه الدورية المرموقة ما أرى أنه تحدياً يواجه استخدام النظرية الاقتصادية الكلية (الماكرو اقتصادية) فى وضع سياسات التوازن والنمو الاقتصاديين. فعندما يواجه الاقتصاد حالة اختلال مالى ونقدى أو بطالة متزايدة، هل يلجأ أصحاب القرار إلى الوصفة الكينزية، أم السياسة النقدية؟ تكمن المعضلة فى أن أياً من المنهجين سيكون له منطقه الواضح فى الربط بين المتغيرات الاقتصادية وآليات تفاعلها، وتأثثراتها المتبادلة، ونتائجها المتوقعة. كيف نحكم على صواب أى النظريتين، وصلاحية كل منهما لحل المشكلة القائمة؟ بعيداً عن الاقتتاع الفكرى المسبق لصاحب القرار ومسنتاريه، يبدو أنهم سيكونون فى حاجة إلى "معيار" لإيه" للحكم على ملاعمة الحل الكينزى أو النقدى. ما هو هذا المعيار؟ لم أتطرق فى مقالتى المشار إلبها أعلاه إلى هذا السؤال، وربما لم تخطر ببالى الحاجة إلى طرحه أساساً. فى غضون إعداد تلك المقالة كانت قد صدرت النسخة الانجليزية من كتاب يحمل عنواناً مُلْفِتاً، لم يَذِرْ بخلدى أهميته لارتباطه بكل ما تعلمته ومارسته فى نطاق علوم الاقتصاد، عنوان الكتاب هو "|قتصاديات الصالح العام". للاقتصادى الفرنسى الحائز على نوبل(Jean Tirole) وعبر قراءة الكتاب وجدت أن "الصالح العام" ربما يوفر معياراً كافياً وضرورياً لاختيار سياسة اقتصادية ما، وقرار مالي (استثماري) محدد، ويصلح مؤشراً كاشفاً لأفضلية أى من السياستين: الكينزية والنقدية، فى مواجهة المشكلة الاقتصادية المطروحة. فما هو مفهوم الصالح العام؟ ماهو دور علم الاقتصاد فى السعى نحو وضع سياسات اقتصادية يكون مبتخاها هو مصلحة المجموع؟ هل اقتصاديات الصالح العام تعمل فى إطار أى نظام اقتصادى/ إجنماعى؟ سنعرض باختصار فيما يلى وجهة نظر المؤلف فى تلك المسائل. 
يتطلب تعريف الصالح العام- الهدف الجماعى للمجتمع- حُكْماً قيمياً، إلى حد ما، كما يرى المؤلف، فالحكم والتقدير الذى يقوم به كل منا يعكس بالضرورة تفضيلاتتا الفردية، المعلومات المتوفرة لنا، ومواقعنا فى المجتمع. وحتى عندما نتوافق على بعض الأهداف الأساسية المرغوبة، فقد نبقى على خلاف حول الأهمية النسبية للمساواة، القدرة الثرائية، البيئة أو العمل مقابل الحياة الثخصية دون الحاجة للتذكير بأبعاد شخصية أخرى، مثل القيم الأخلاقية، الدينية والروحية، التى تتباين حولها الآراء كثيراً. وعلى الرغم من ذلك يمكن التخلى عن بعض التعسف الذى ينطوى عليه تعربف الصالح العام، إذ يقتضى الأمر أن يتجرد المرء- عند تقدير حُكْمِه وإختياراتهـمن خصائصسه ووضعه (مكانته) فى المجتمع ، ويضع نفسه "خلف ستار الجهل"، وعدم المعرفة لكى يوضح فكرته يُعيد طرح السؤال عن طبيعة وشكل المجتمع الذى قد يرغب شخص ما فى العيش فيه. وبطبيعة الحال فإن المقصود بالمجتمع ليس "المجتمع المثالى"، حيث- على سبيل المثالـيقوم تلقائياً المواطنون، العمال، قيادات الأعمال، السياسيون بوضع الصالح العام قبل مصالحهم الثخصية. وحتى لو أن الناس لا يسعون باستمرار إلى تحقيق مصالحهم المادية، فإنهم غالباً يعطون الأولوية لمصالحهم الذاتية على المصلحة العامة، الفثل فى مراعاة الحوافز الفردية، والسلوك المتوقع للأفراد، أدى فى الماضى إلى شيوع النظم الثمولية والمؤسسات المركزية. وعلى ضوء هذه الخلفية يؤكد المؤلف أن نقطة البداية فى كتابه تتمتل فى المبدأ التالى: سواء كانوا سياسيين، مديرين، أو عاملين، سواء كانوا متعطلين، متعاقدين مستقلين، مسئولين كبار، وله مزارعين، أو باحثين- أياً كان موقعهم فى المجتمع- يتصرف الناس بناء على"الحوافز" التى يواجهونها. إن الحوافز المادية أو الاجتماعية، متواكبة مع تفضيلاتهم الذاتية، هى التى تحدد سلوكهم، الذى قد يتوافق أو لا يتوافق مع المصلحة العامة. ومن هنا فإن تحقيق الصالح العام يتطلب بناء مؤسسات قادرة على بلوغ الانسجام- بأكبر قدر ممكن- بين مصالح الأفراد والمصلحة 
ومن هذا المنطلق يقرر المؤلف أن اقتصاد السوق ليس هدفاً فى حد ذاته. وفى أحسن

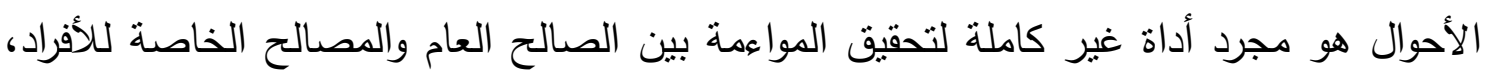

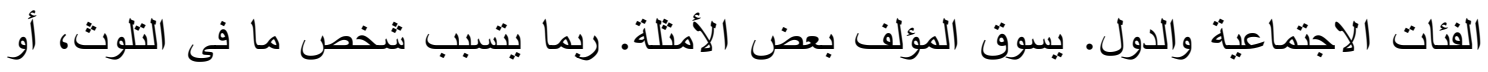

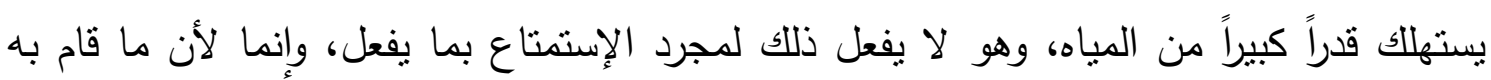

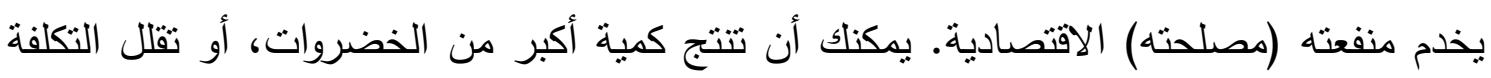

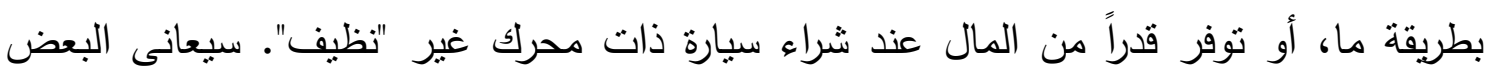

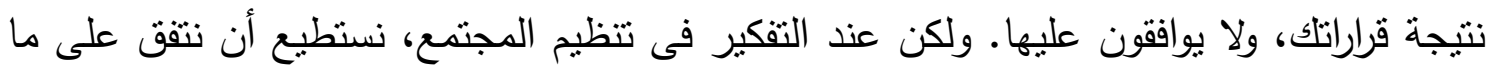

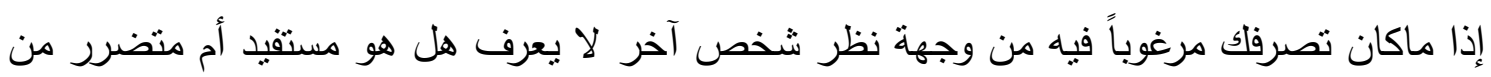

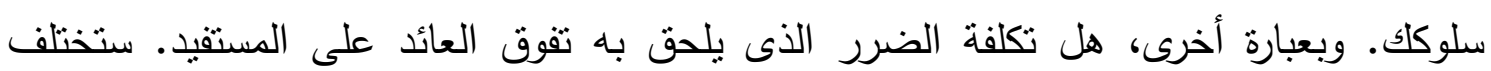

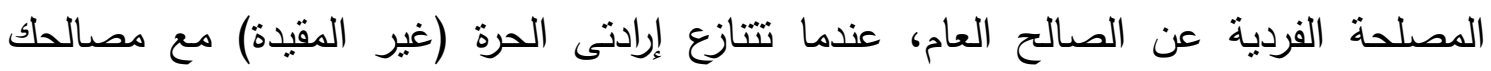

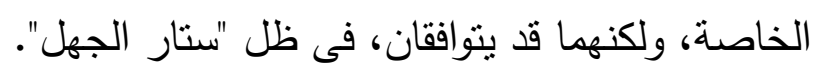
ثمة فائدة أخرى للتفكير من وراء ستار الجهل تكمن فئ فئ أن "الحقوق" تحتاج إلى رشادة

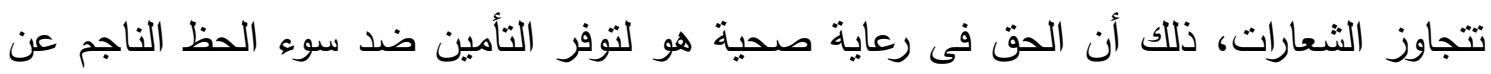

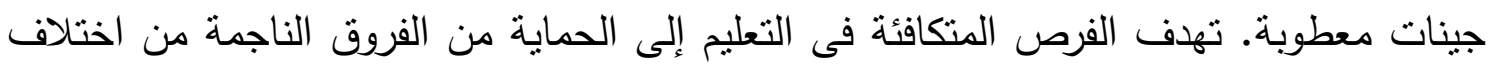

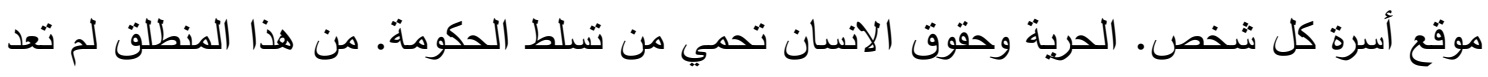

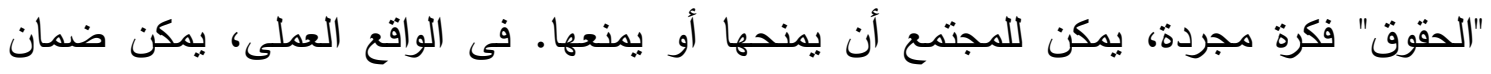

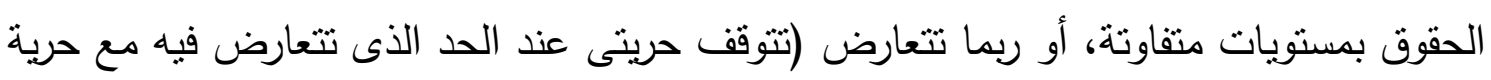
الآخرين)، وهو ما يجعل الحقوق مسألة نطبيقية.

إن نقطة البدء فى مطلب الصالح العام هى تحقيق "الرفاهة"، فى ظل ستار الجهل. فهى لا تحكم مسبقاً على الحلول، وليس هناك معيار سوى المصلحة الجماعية. هى تسمح بالاستعمال

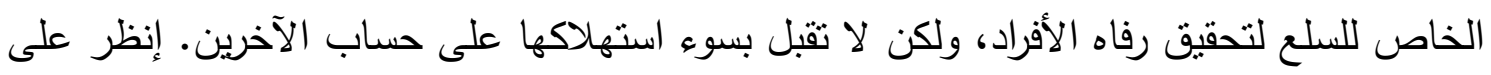

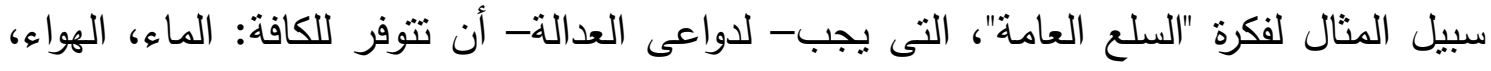

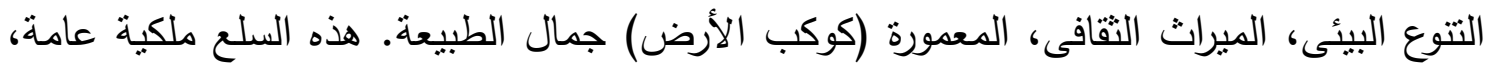

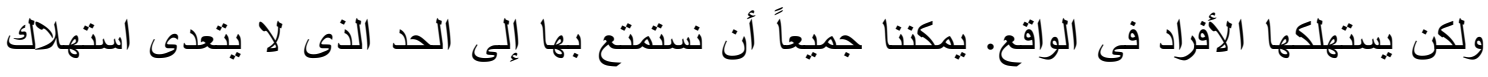
V 
طرف على استهالك طرف آخر (يصدق ذلك أيضا على المعرفة، إنارة الثوارع، الدفاع عن

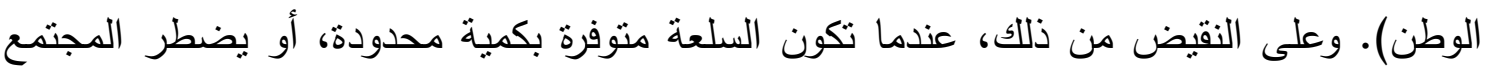

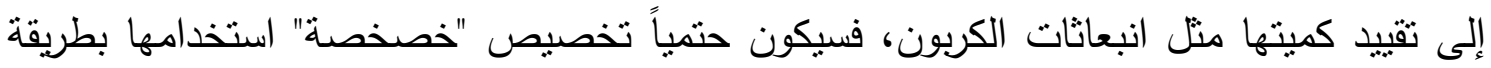

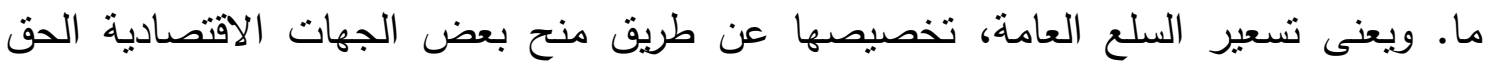

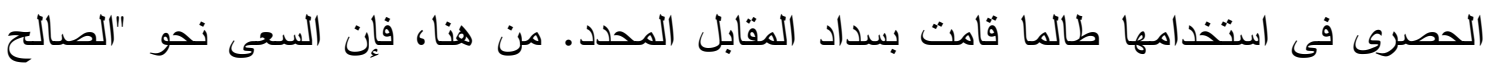

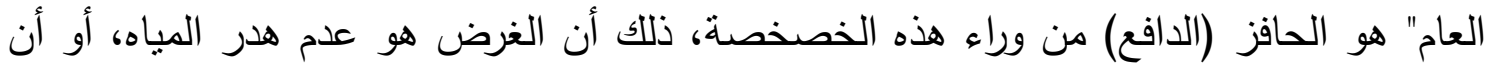

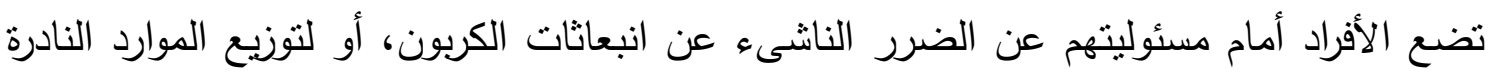
لمن يقدر على حسن استعمالها.

إنتوى المؤلف الإجابة عن سؤاله الثانى من خلال طرح تلألك الأمنتة المشار اليها أعلاه.

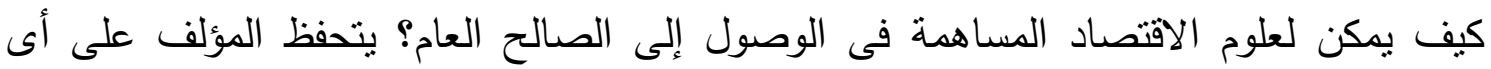

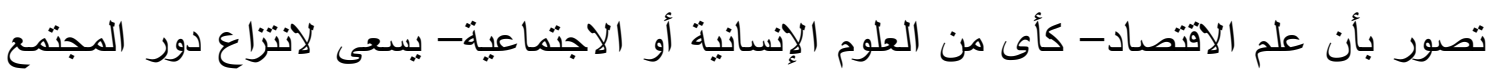

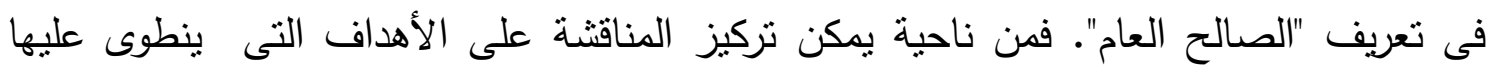

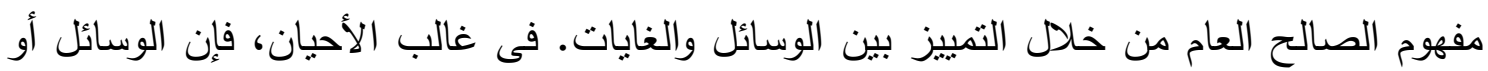
الأدوات- سواء كانت مؤسسات (متل السوق)، أو سياسة اقتصادية- تكتسب حياة قائمة بذاتها، وتتسى الغرض الذى أنشئت من أجله. بل ربما تتنهى إلى العمل ضد مبدأ أو فكرة الصالح العام.

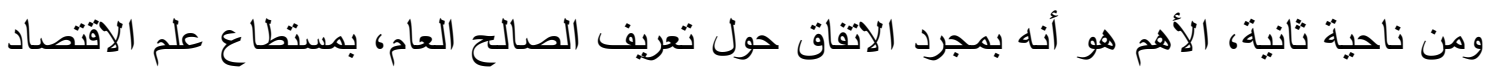

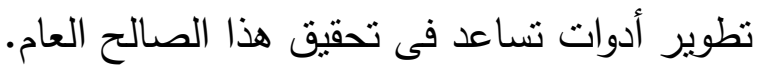
ويؤكد المؤلف على أن الاقتصاد ليس فى خدمة الملكية الخاصة، والمصلحة الفردية، ولا

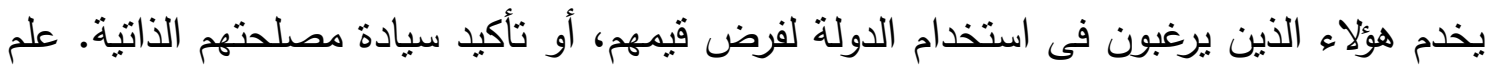

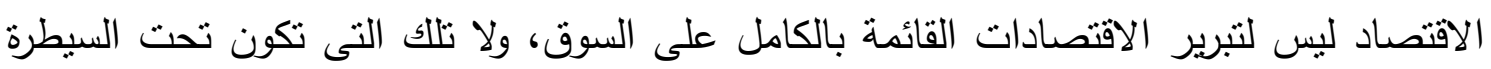

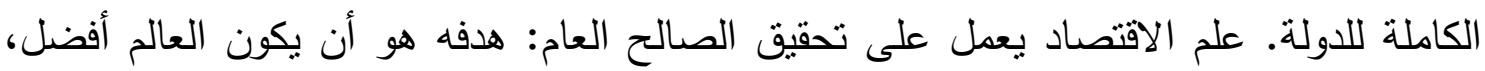

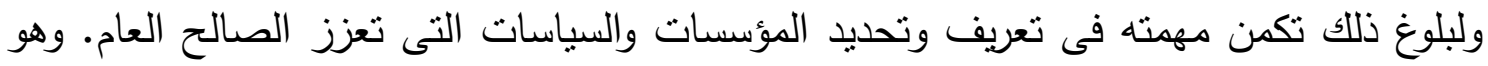
فى سعيه نحو رفاه المجتمع، يتضمن الأبعاد المتصلة بالأفراد والمجموع معاً، ويقوم بتحليل 
الحالات (والأحوال) التى تتوافق فى ظلها متطلبات الرفاه الجماعى، وتلك التى تعوق فيها الدصالح

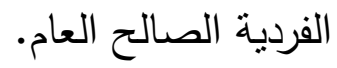

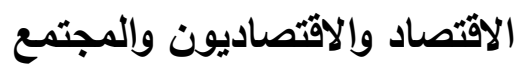

يخصص المؤلف أول جزأين فى كتابه لمناقتشة دور علم الاقتصاد فى المجتمع: موقع "الاقتصادى"، عمل الباحث فى مجال الاقتصاد، علاقة الاقتصاد بالعلوم الاجتماعية الأخرى،

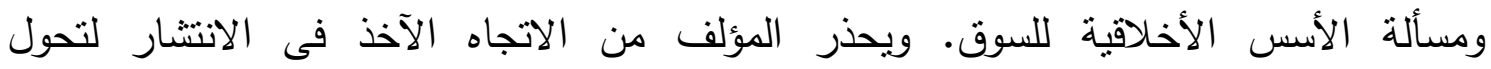
الاقتصاديين إلى شخوص إعلامية، بينما يجب أن يكون التركيز على علم الاقتصاد ذاته والقضايا

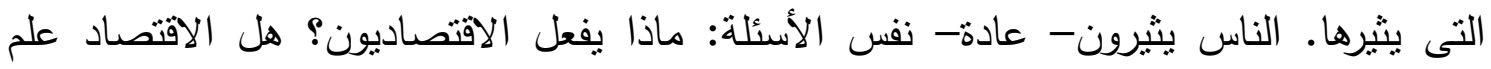

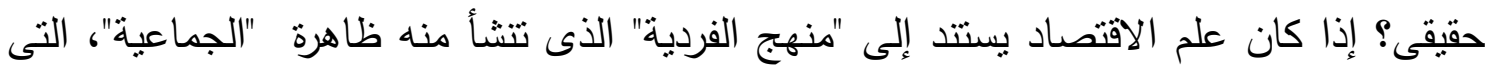

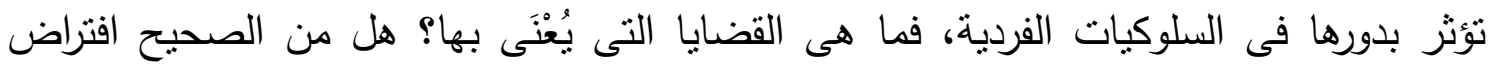

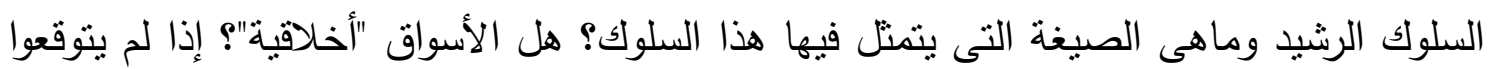

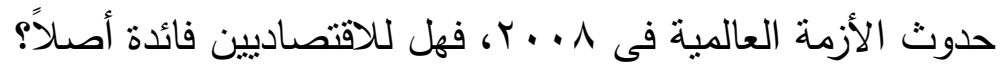

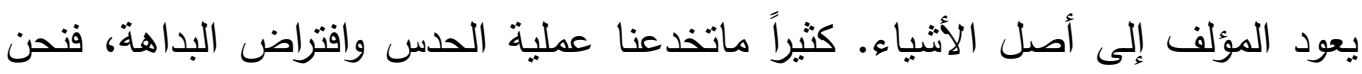
ضعفاء ونستسلم لتحيزات ومعتقدات محددة. عندما نبحث مشكلة اقتصادية، فإن أول إجابة تطرأ لنا

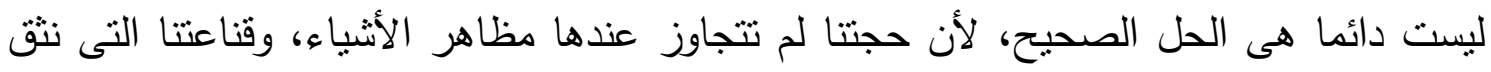

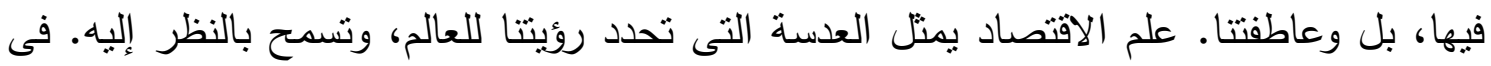

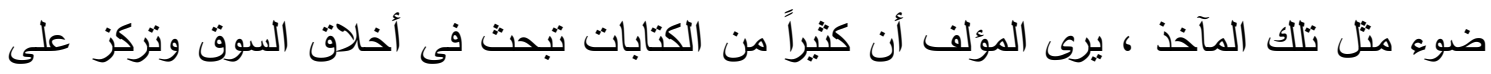

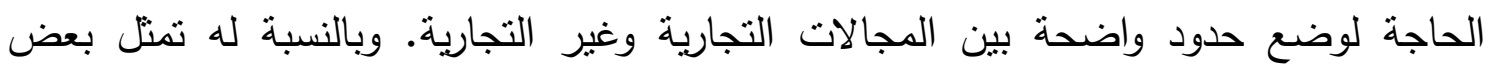
الانتقادات للسوق مجرد إعادة صياغة لمفهوم حالات "فثل السوق" التى تستوجب تدخل السلطة

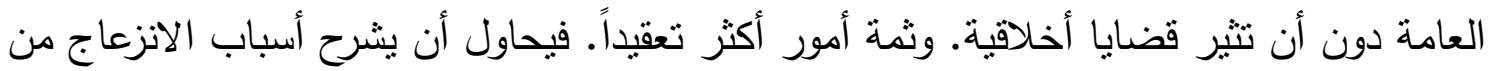

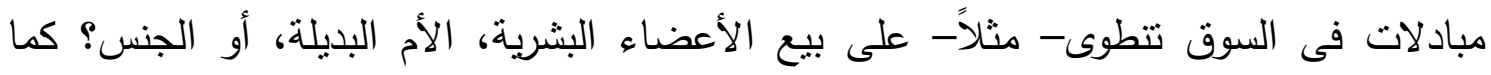
يحاول التركيز على أنه بينما قد تمثلكنا مشاعر السخط من سلوك فردى شاذ الهاذ أو الحاجة إلى تتظير

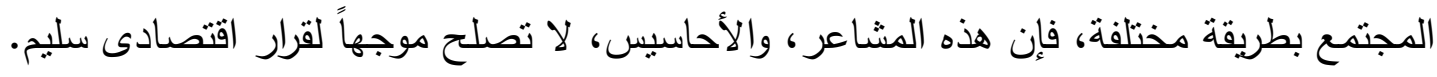


أما عن وظيفة الاقتصاديين، فهو يعتقد أن دورهم ليس اتخاذ القرارات ولكن تحديد أنماط هيكلة الاقتصاد، والتعريف بالتطورات الحديثة لعلم الاقتصاد. يواجه الاقصاديون عند القيام بدورهم على الوجه المناسب صعوبتني، الأولى - كما يزعم البعض- تهمة عدم الكفاءة ونقص الفاعلى الفاعلية.

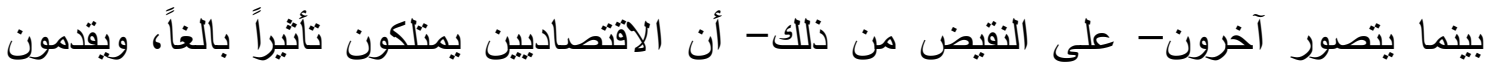

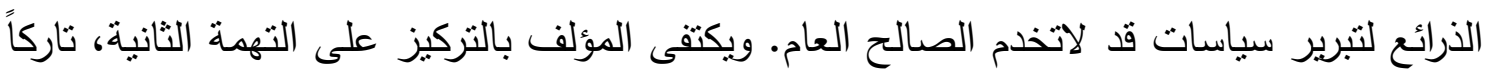

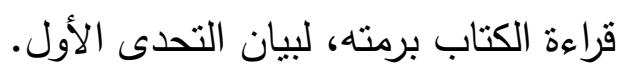

صحيح أنه من المشروع التساؤل عن دور الاقتصادى فى المجتمع، ولكن المؤلف يذكرنا

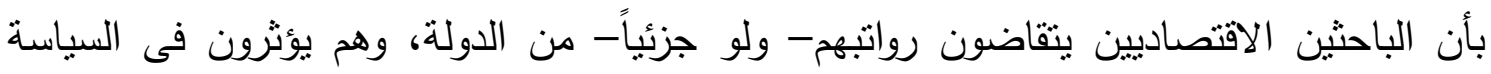

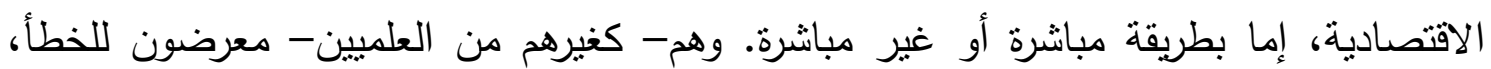
ولكن يلزم أن يكونوا محل المحاسبة. قد يتمتع الباحثون الاقتصاديون بحياتهم الأكاديمية، ولكن يلزم

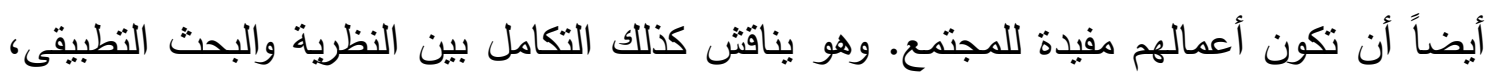

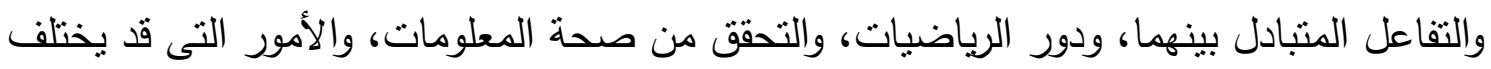

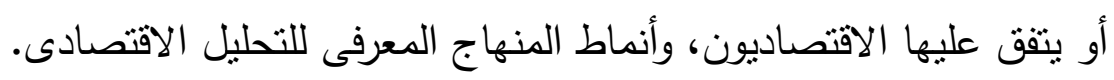

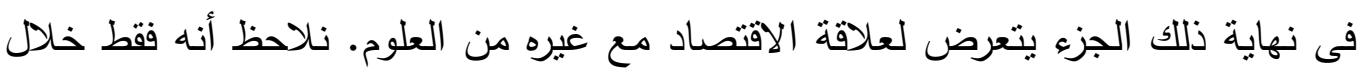
القرن العشرين بدأ تطور الاقتصاد كعلم مستقل، من خلال افتراض أن متخذى القرار (مستهلكين،

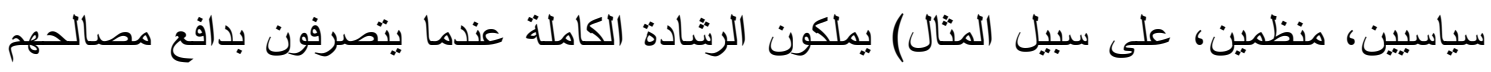

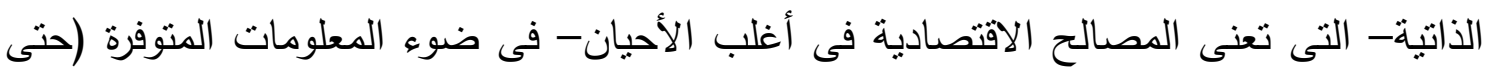

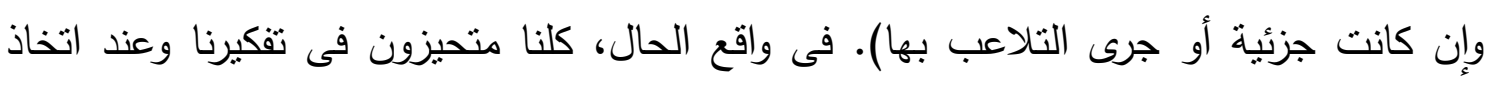

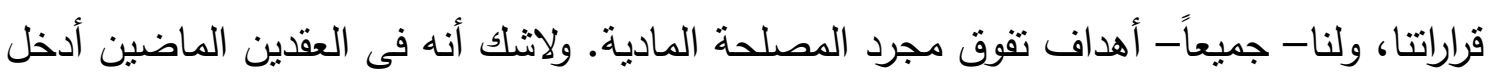

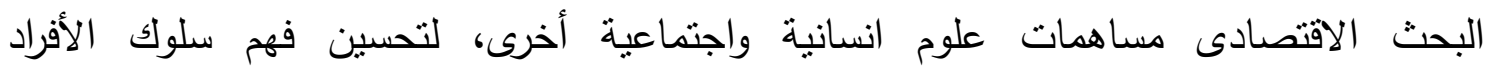
والجماعات، ووضع القرار السياسى، وصياغة النتريعات.

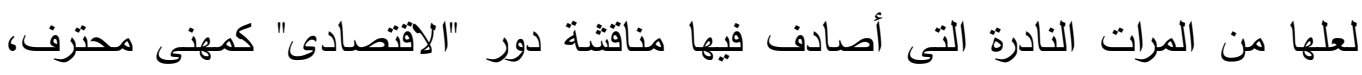

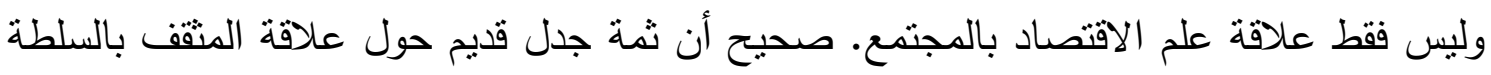


(بإعتبار أن الاقتصادى الحَقْ قد يُعَدُ فى زمرة المنقفين)، ولكن كتاب اقتصاديات الصالح العام تتاول هذه المسألة بقدر غير محدود فى الروئة والواقعية. وقد لفتت هذه المناقثة انتباهى لدقالة

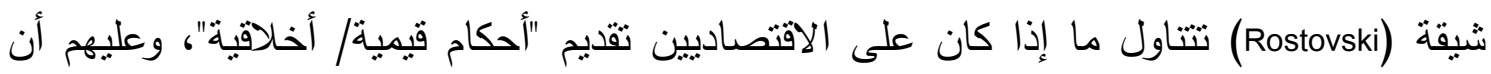

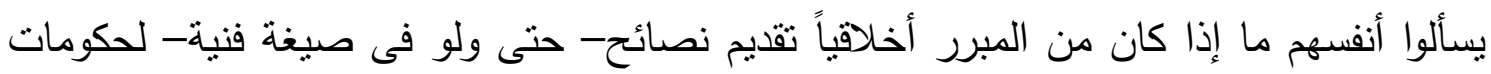

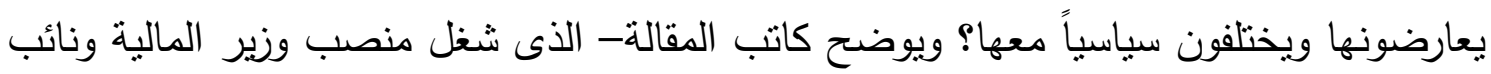

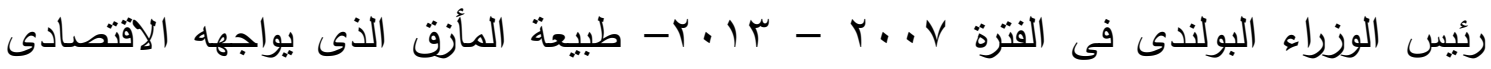

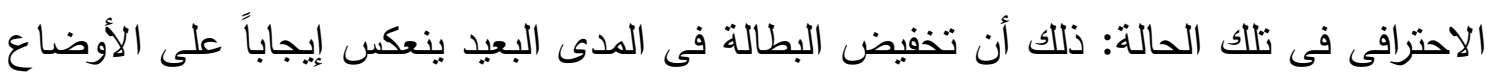

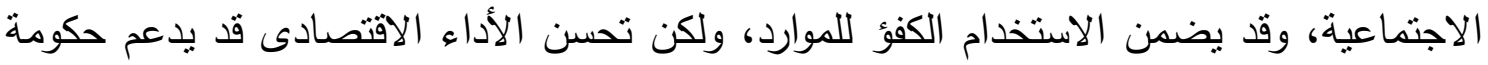

$$
\text { هو يعارضها (وربما فى موقف المناوىء لسياساتها). }
$$

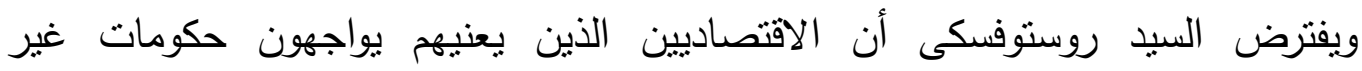

ديموقراطية، وقد يستتدون إلى أحد توجهات ثلاثة لتحديد مدى استعدادهم وقبولهم لتقديم النصائح

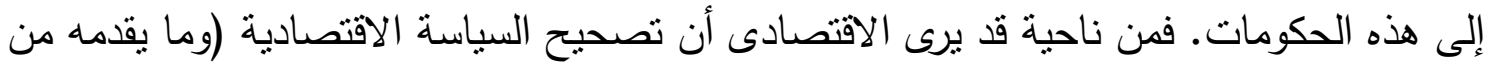

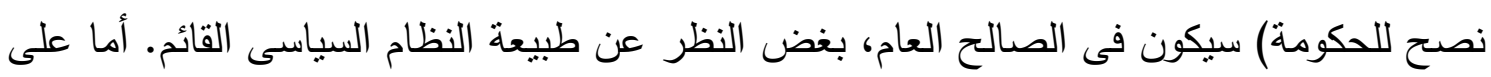
النقيض من ذلك هناك من ينتكك فى جدوى تقديم المشورة أو اقتراح حلول تتجاوز أسس "|(قتصاد

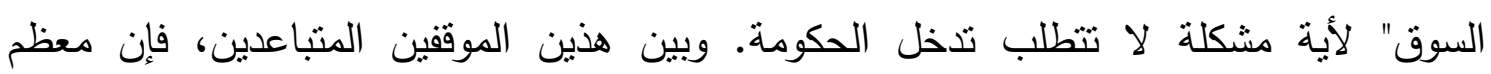

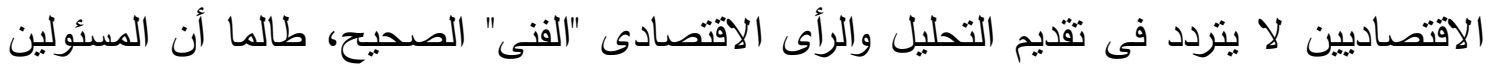

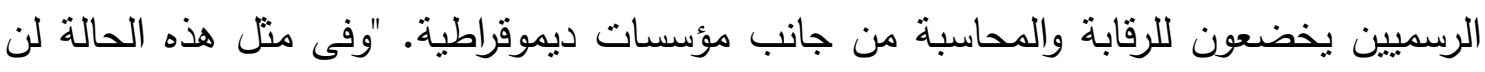

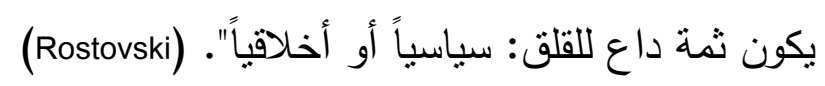
ومما يصب فى غمار موضوع الكتاب الذى نحن بصدده "|قتصاديات الصالح العام"

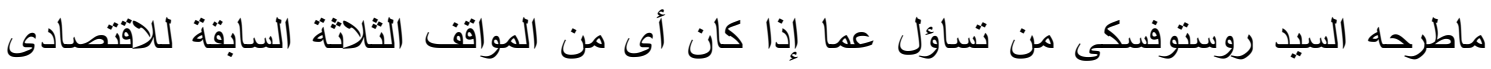

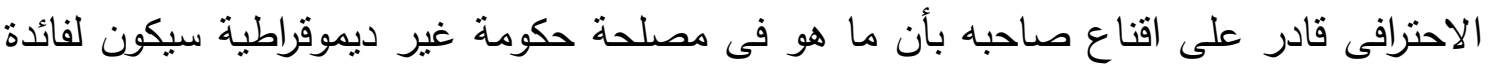

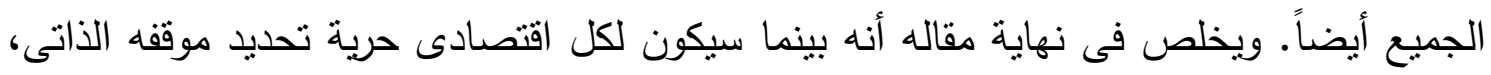

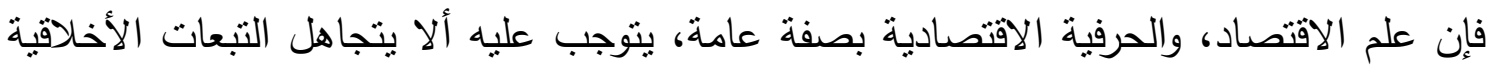
لترجمة التحليل الاقتصادى إلى ممارسة واقعية. 


\section{كيف يواجه الاقتصاد التحديات العملية؟}

يخصص المؤلف حوالى نصف كتابه (عشر فصول) لمناقثة ما يعتبره التحديات

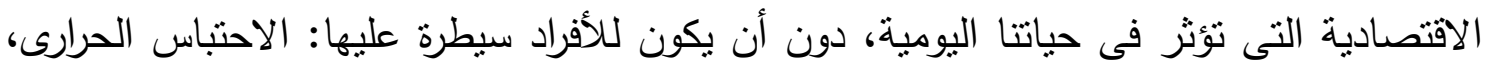
سوق العمل، التمويل، المنافسة والسياسة الصناعية، العلاقة مع العالم الرقمى، الابتكار، والسوق

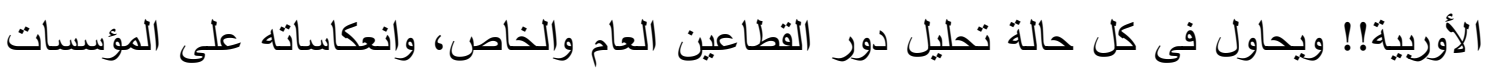

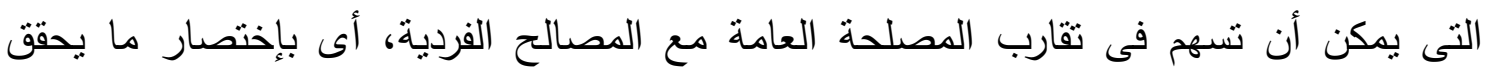
الصالح العام.

ويسلط المؤلف الضوء- فى نهاية الكتاب- على مسألة يراها جوهرية، تتصل بنظرية المعلومات، إذ يرى أن القرارات التى يتخذها الفاعلون الاقتصاديون (العائلة، الثركة، الدولة) تكون

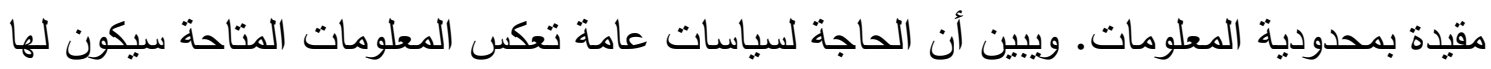
تبعات على صياغة سياسة التشغيل، حماية البيئة، السياسة الصناعية، والتتظيم القطاعى والبنكى. أما فى القطاع الخاص فإن عدم الاتساق فى البيانات سيؤثر فى مؤسسات الحوكمة وأنماط

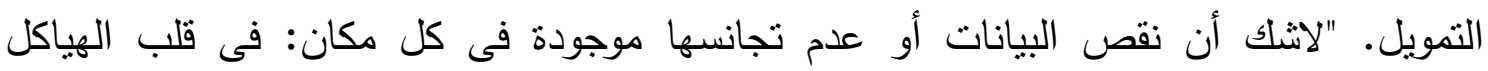
المؤسسية والاختيارات السياسية، وهى كذلك فى صلب اقتصاديات الصالح العام"، كما يقول

الدولة والسوق: هل هما بديلان ؟

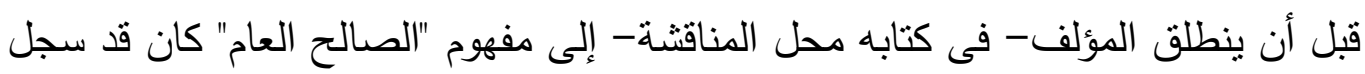

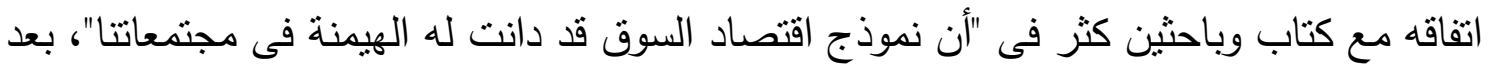

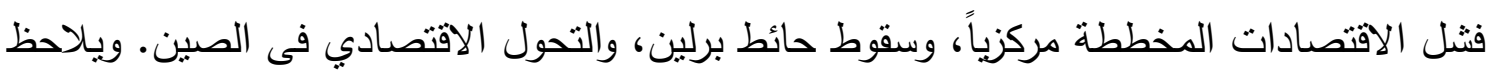

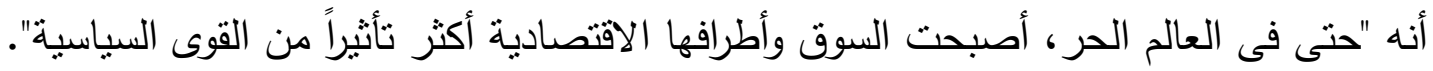

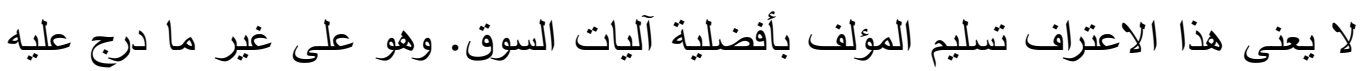

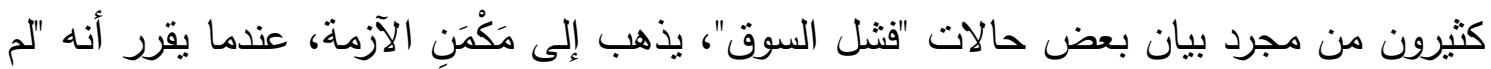

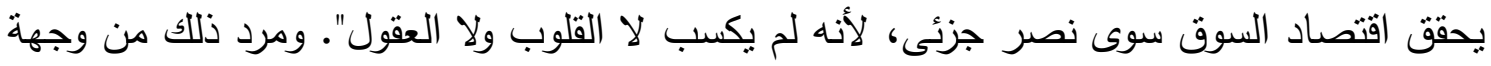


نظره، التى يوجزها فى عنوان كتابه، "أنه بالنسبة لكثيرين، فإن السعى نحو تحقيق الصالح العام،

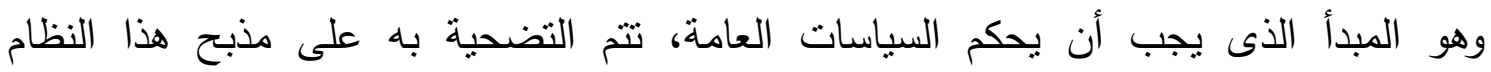
الاقتصادى الجديد". يعدد الكاتب الانتقادات النى توجه لهذا النظام ويسجل سماته الحالية، كالأزمة

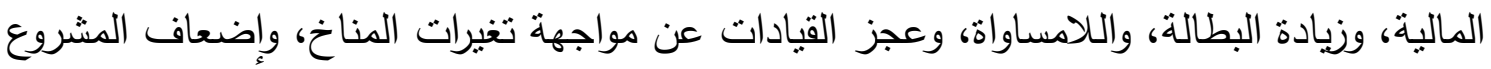

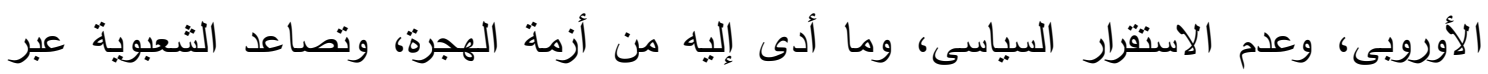

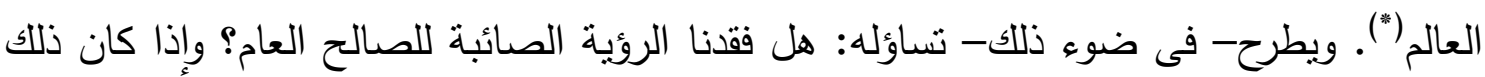

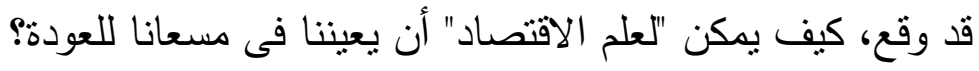
لعل المسألة التقليدية التى يطرحها مؤلف الكتاب تتصل باللاعبين الأساسيين فى الحياة

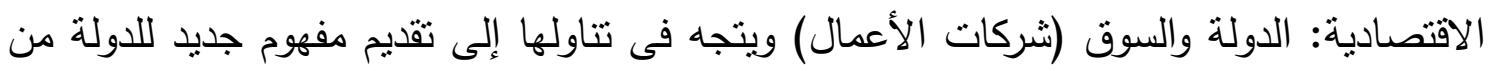

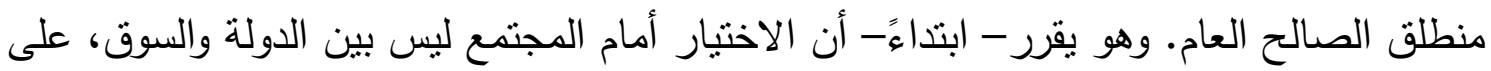

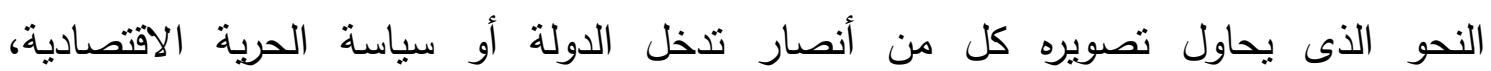
"السوق والدولة متكاملان وليسا متتاقضين، لا ينفى أى منهما الآخر ". وفى عبارة مركزة يوجز طبيعة العلاقة: "تحتاج السوق إلى تتظيم (ضوابط)، وتتطلب الدولة

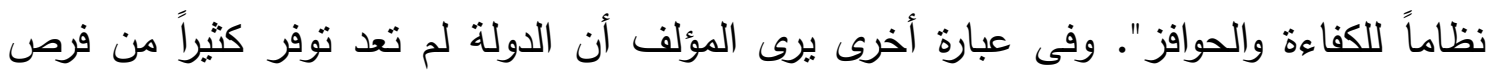
العمل من خلال القطاع العام، ولا تتتج السلع والخدمات المختلفة عن طريق الثركات العامة. لقد

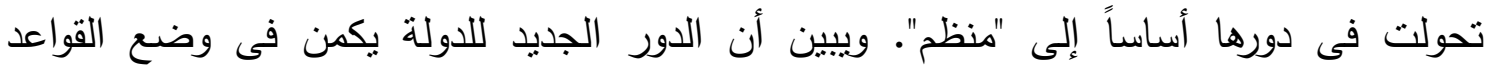

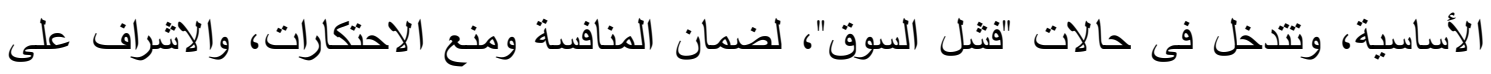

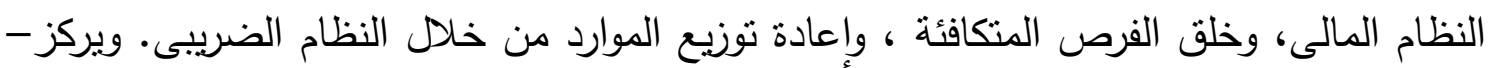

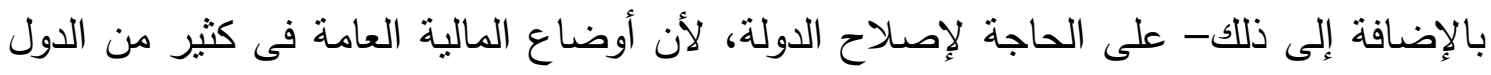

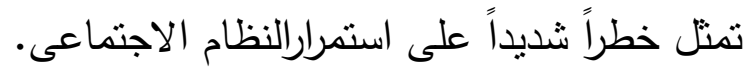
ويتتاول المؤلف على الجانب الآخر دور الثركات (الوحدات الإنتاجية والخدمية)، ويشرح

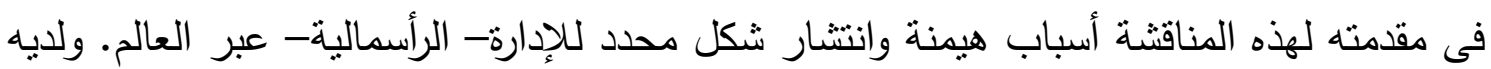


أن هذا الثكل يمنح سلطة القرار لحملة الأسهم، أو الدائنين عندما لا تسدد الديون. بينما هناك

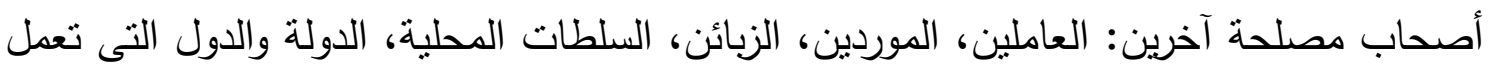

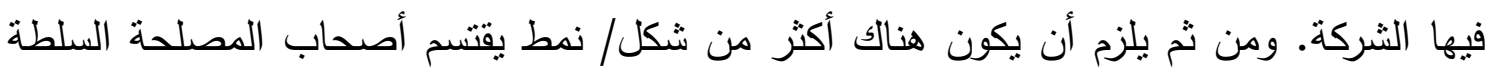

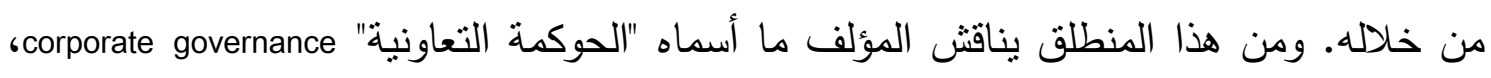
والمسئولية الاجتماعية للشركات وللاستثمار • ويطرح تساؤله حول دلالة هذه المفاهيم، وما إذا كانت

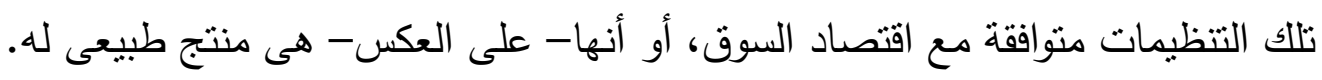

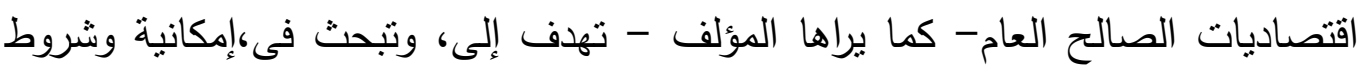
النوليف بين الدصالح الفردية ومصلحة المجتمع، وكذلك أساليب التوافق بين سياسة الدولة ومؤسسات السوق. كلام طيب احتواه الكتاب محل قراءتتا الحالية. وعلى الرغم من ذلك، فإن كأن كثيراً

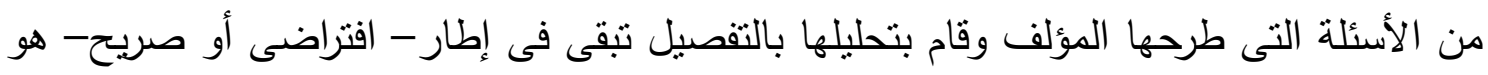

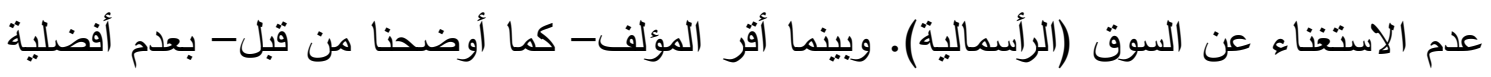

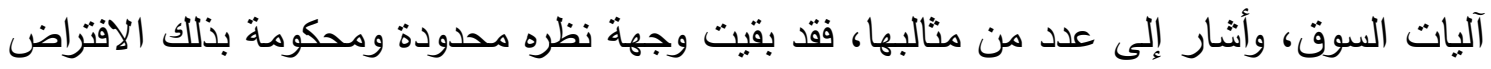
حول الأسس الاقتصادية والسياسية للنظام القائم.

\section{هل تصمد الرأسمالية:}

بعد أن بدا وكأن الجدل قد وصل إلى منتهاه حول طبيعة النظم الاقتصادية: انشتراكية

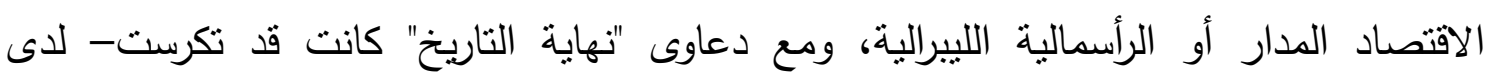

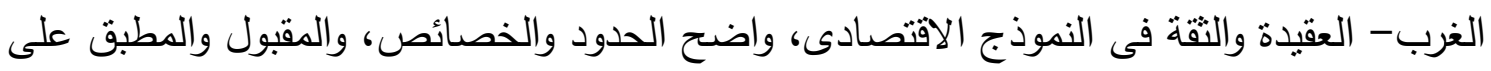

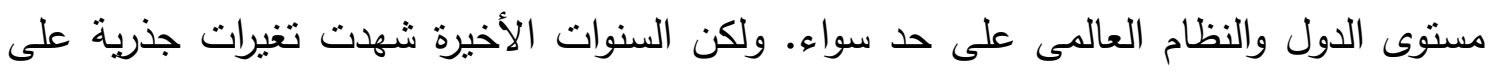

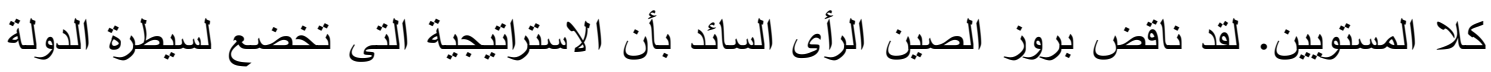

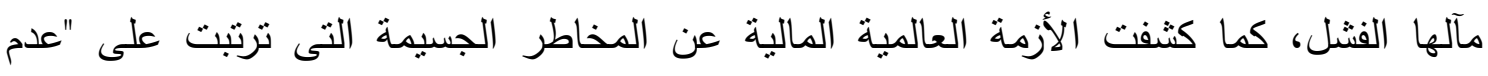

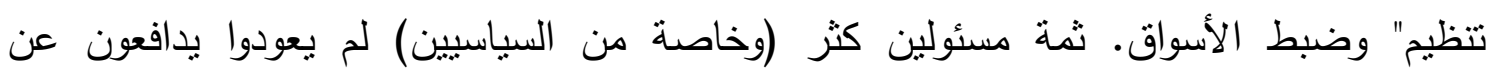
"رأسمالية السوق الحرة" سواء من منظور النمو الاقتصادى أو منافع العولمة (ولماهية (Ngaire Woods). 


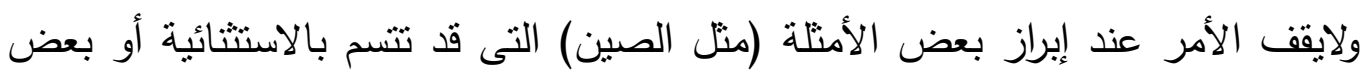
الأوضاع الخاصة، ولكن ثمة وجهات نظر تذهب إلى فثل النموذج الذى يتنباه ما يطلق عليه "توافق واشنطن". الفكرة الرئيسية البسيطة هنا تكمن فى أن البلد سيستقيد من تبنى آلية أسعار

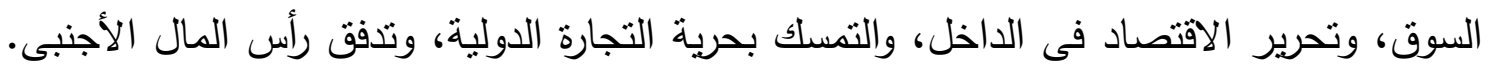

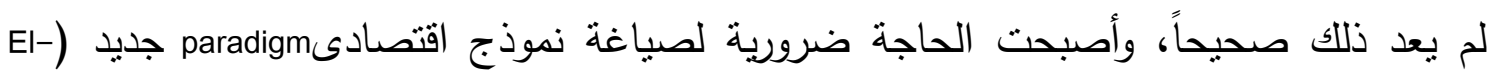
Erian تطوير فهم أثنمل للعلاقة بين نمو وتحرير القطاع المالى وبين الاقتصاد الحقيقى (العينى)، ولتأثثر

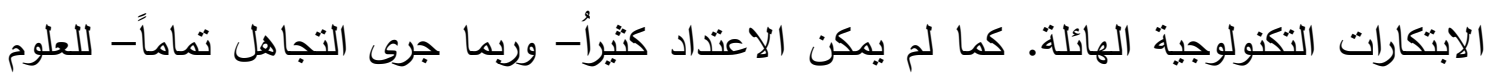

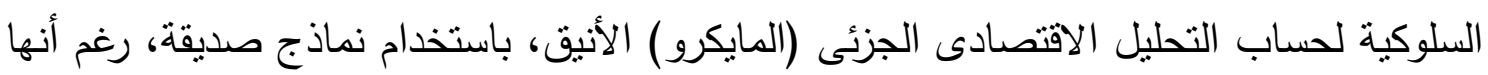

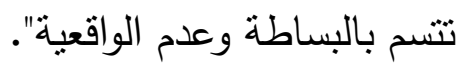
وتعويل الاقتصاديين على قواعد وأسس ميكانيكية لتفسير - بل والتأثثر على- النتائج

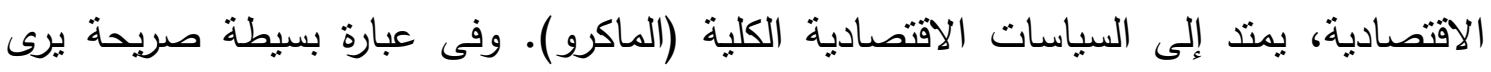

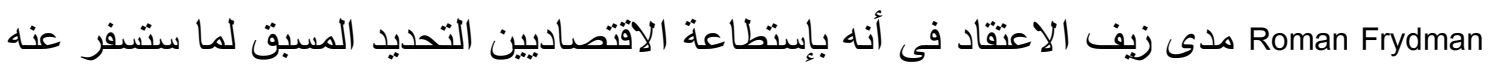
النتائج الاقتصادية، ومن ثم مستوى النشاط الاقتصادى. ( كانت حالة الأزمة المالية العالمية مثالاً

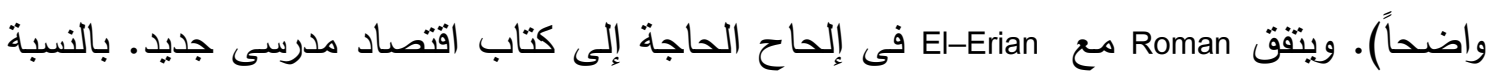
له فإن السؤال ليس ما إذا كان "المحفز المالى" كاف، أو أن مقداراً أكبر لهذا الدحفز أكثر نفعاً،

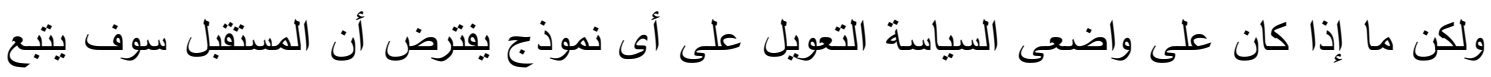
الماضى بشكل ميكانيكى. ويسجل بدوره أن هناك انهيار السوق العقارى (فى غمار الأزمة العالمية)

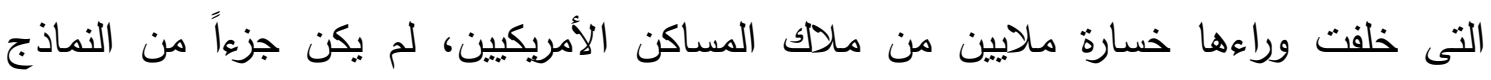

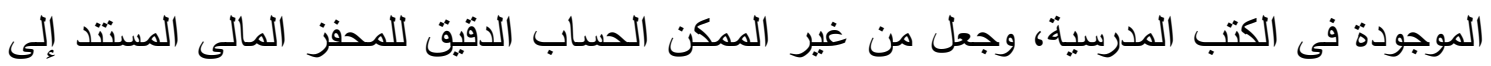

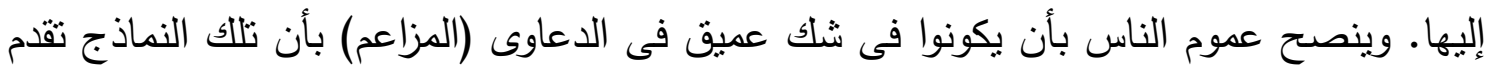
أى أساس علمى لوضع السياسة الاقتصادية. هناك كذللك من يعنقد أن المشكلة الرئيسية تكمن فيما أصاب الفكر الاقتصادى الغربى من جمود وقحط الدفكرين الاقتصاديين. ويقدم Andrew Sheng الدلالة على ذلك. فكما لاحظ سكيدلسكى 
فإن "أزمة الكساد العظيم فى الثلاثينات من القرن الماضى أنتجت الاقتصاديات الكينزية. الركود التضخمى فى السبعينيات تمخض عنه فكر ميلتون فريدمان الذى أحدث ثورة فى النظرية النقدية.

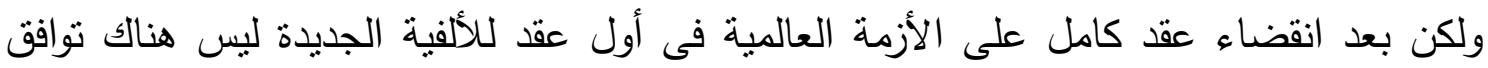
على تحول جوهرى فى مساق الفكر الاقتصادى الغربى".

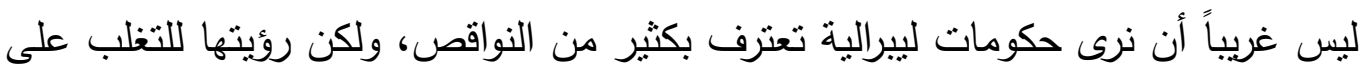
مثالب النظام لا تتطوى على قبول بتغيير الأسس النى يقوم عليها. إذ نقراً عن السيدة ماى، رئيسة

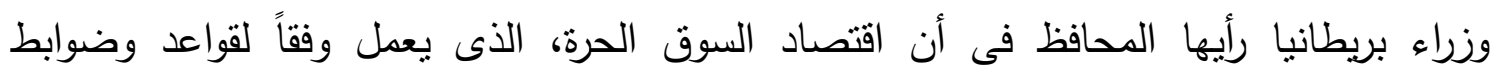

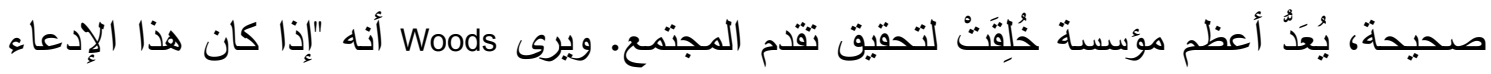

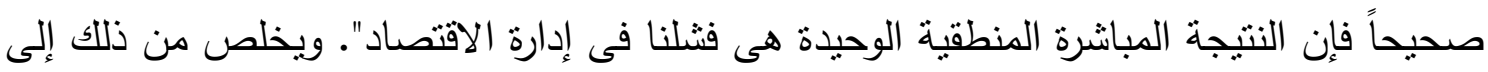

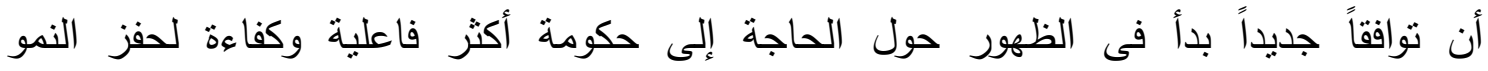

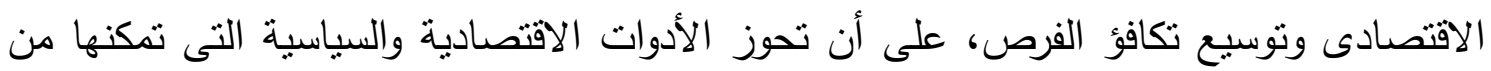
إعادة تأهيل رأسمالية السوق الحرة. وكما يرى العريان لازال ثمة دور مهم يجب على الاقتصاديين وصناع القرارات أن يؤدوه

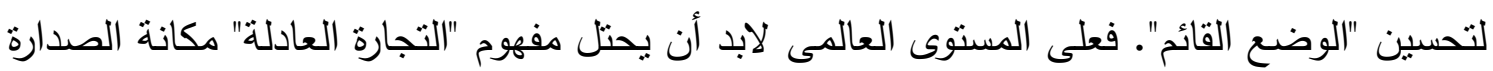

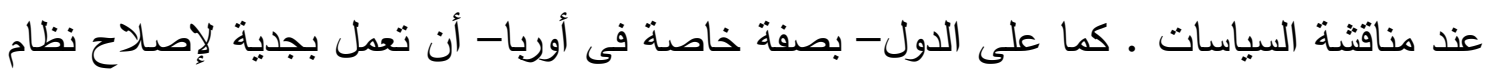

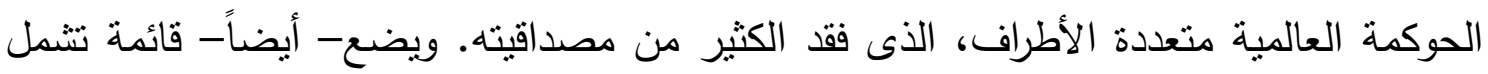
قضايا جديرة بالتحليل المعمق، متل التأثير المتبادل للاقتصاد العينى والقطاع المالى، مسألة التوزيع وانعكاساتها على الضغوط التى تتعرض لها الطبقة المتوسطة، والفئات المستضعفة، والتغيرات الهيكلية التى ينطوى عليها التقدم التكنولوجى.

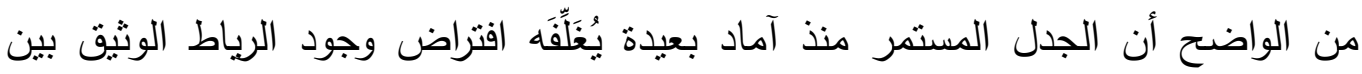

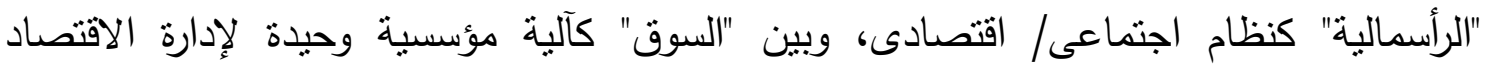

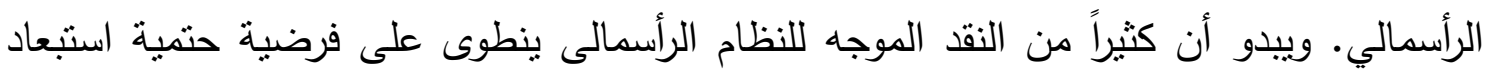

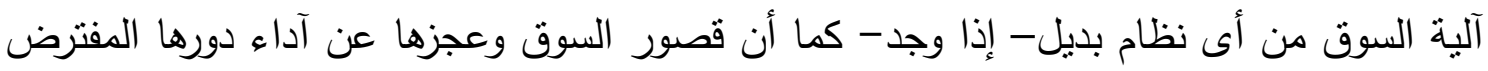


يرجع إلى طبيعة وخصائص النظام الرأسمالى ذاته. تستحق هذه المزاوجة المراجعة. ويمكن أن نرصد مواقف متباينة فى هذا الاتجاه. هناك- من ناحية- التصور بأن الرأسمالية باقية، وتمنتل

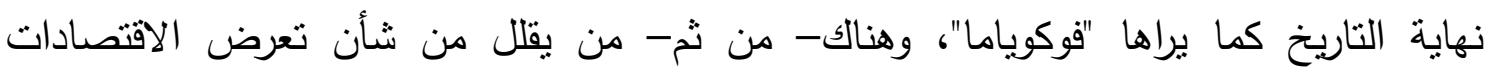

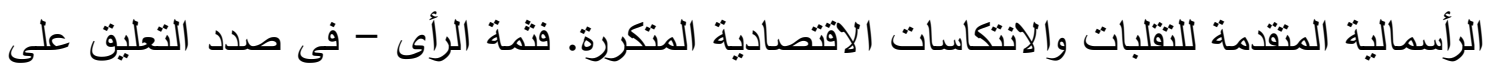

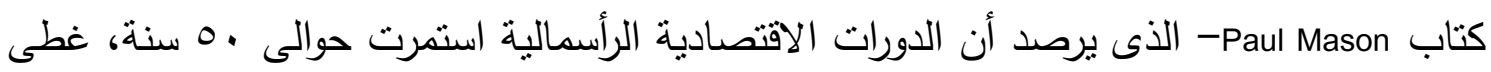

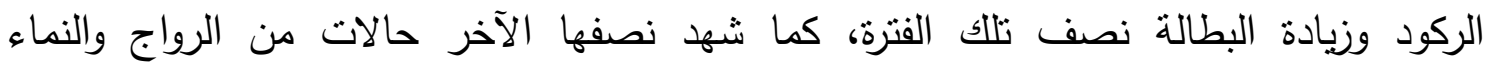

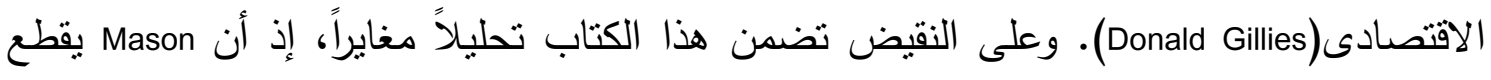
بأن الرأسمالية كنظام مركب وقادر على الثأقلم والمرونة قد بلغ حدود قدرته على النأنأقلم. بل ينتباً

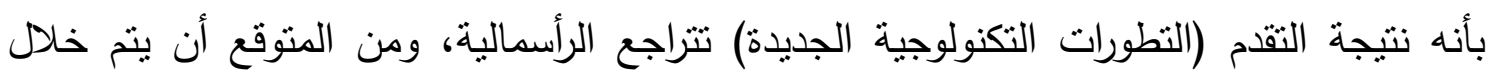
بضعة عقود من الزمن إحلال نظام اجتماعى/ اقتصادى جديد، بطلق عليه "ما بعد الرأسمالية".

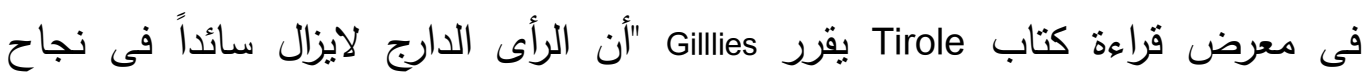

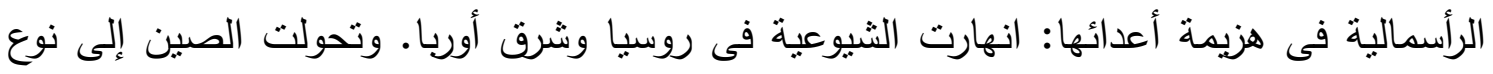

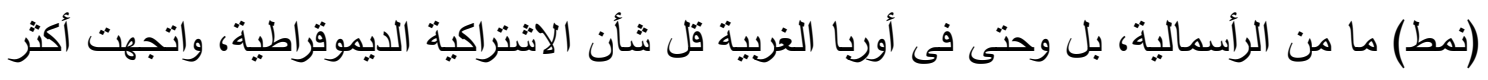

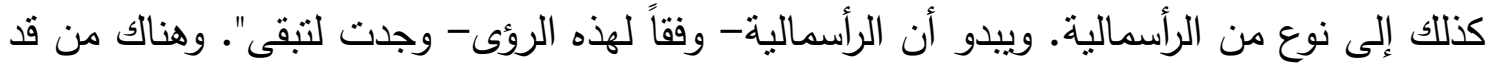

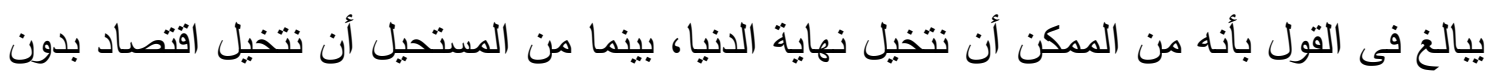

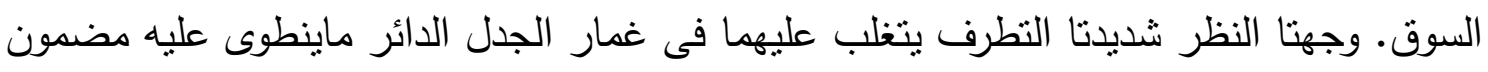

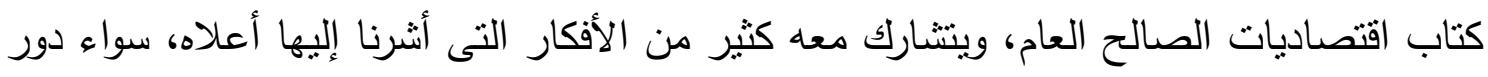

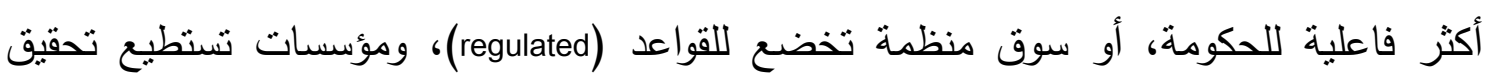
توافق مصلحة الفرد مع المجتمع. وقبل أن أختم مقالى هذا أود أن ألفت النظر إلى بداية مناقثة بعض ما كثنفت عنه معجزة الصين الاقتصادية، ومسئولية "المفكرين غير الغربيين" عن دورهم للتوليف بين الرؤئى والآراء

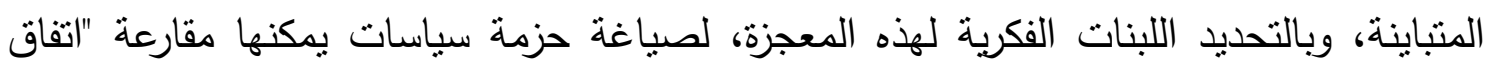

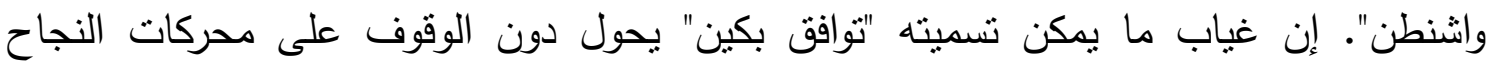

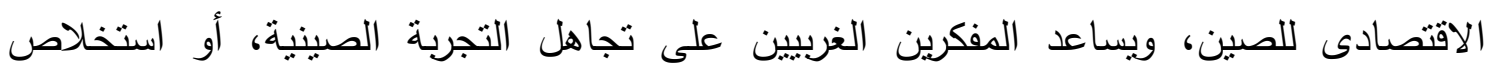




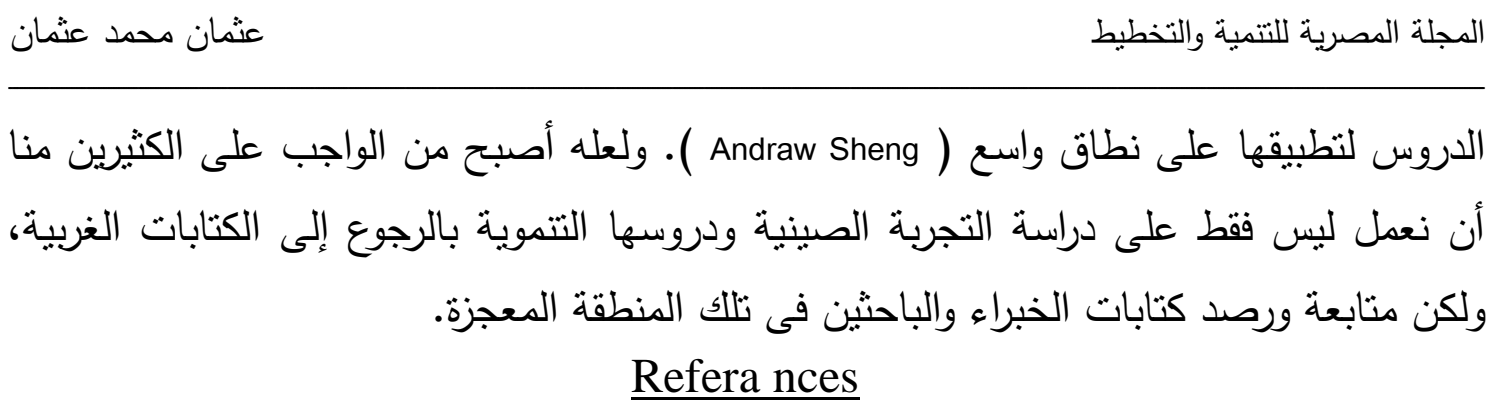

- Andrew Sheng, The Asian Values Debate Returns, Project syndicate, Mar.2, 2018.

- Donald Gillies, Pual Mason's Postcapitalism, real-world economics review, issue no. 73.

- Jacek Rostowski, Should Economists Make Moral Judgments?, May 25, 2018

- Jean Tirole, Economics for the Common Good, Prinston, 2017

- Mohamed A. El-Erian, Working Towardthe Next Economic Paradigm, Project syndicate, Feb 27, 2018.

- Ngaire Woods, The Case Against Free-Market Capitalism, Project syndicate, Oct 12, 2017.

- Roman frydman, Michael D. Goldberg, Did capitalism Fail?, Project syndicate, Seb 13, 2018. 